\title{
'Only if they pay me...': ideals and pragmatics of post-graduates who teach
}

\author{
Anselma Gallinat
}

Post-graduate tutors form a common part of teaching staff at many departments across the UK. Anyone who has ever been in the position of trying to finish the Ph.D. and teaching simultaneously will remember that life seemed rather difficult at the time. This article explores why post-graduate life appears so complicated, what place teaching duties have in this complexity, and what implications this position has for the teaching post-graduates are engaged in.

Research post-graduates have to balance a number of different but equally vital tasks in order to ensure their successful transition to the category of academic staff. These tasks depend on our perception of the academic profession as one that is occupied with research, the recognition of this research (publications) and the distribution of the research to disciples (teaching). But first of all post-graduates first of all need to gain a Ph.D, often within the three-year deadline. The second task is to publish and attend conferences to facilitate ones career; the third is to gain teaching experience. However, now that funding in the Social Sciences and Arts has decreased, another task needs to be added; this is the necessity to at least partly contribute to one's subsistence through working part-time.

Given that time, as well as money, are scarce resources, post-graduate studentsneed to consider very carefully how best to distribute their energies. This pressure is exaggerated by the conventional schedule of an Anthropology Ph.D.: year one - literature research, year two - fieldwork, year three - all that remains. Although this may not be the case for every student nowadays it seems to affect a siginificant number of students in anthropology. In 2000/2001 when I was stuck in the middle of eastern Germany for an entire year, there was no thinking about publishing or attending conferences. Whilst friends doing history in Durham were busy writing chapters and articles I was tending to my interviews, translating them, writing fieldnotes and diaries, taking photographs; always putting research first. When I returned to Durham panic started to sick through. I needed publications, a network (conferences) and teaching experience, and I needed to finish in time as with the Anthropology Matters J ournal, 2003-1 
coming October my grant would finish. What are the implications of this situation for the student and for the teaching he or she is involved?

Whereas writing of both the Ph.D. and articles or abstracts is an independent and straightforward task, teaching is quite the opposite. Writing is carried out by the individual postgraduate student in their own time. The only administrative task is the yearly submission of progress reports; most other obligations rest with the student and their supervisor. Writing of articles is an even more independent task. Teaching on the other hand depends on a number of factors. First of all, it is arranged externally based on University term and exam times. It therefore has its own schedule that needs to be followed. Whereas writing can be done when there is time or energy and can be postponed when there is neither, teaching demands adherence to its time plan. Essays are due on one day and ought to be back on another, marking takes place during a limited time span. Further in contrast to writing and publishing, teaching consists of more than one or even two tasks. Apart from the time spent in class there is preparation, essay marking and student feedback/consultation forms; all of these obligations including an increasing amount of administrative duties. A sample of all formative work from a range of different grades needs to be copied and stored in module boxes or taken to the senior tutor, student feedback forms need to be analysed, attendance lists kept. Obviously, the amount of administrative duties carried out by any teacher depends on the department and the general organisation of the course. This brief list of duties linked to the 'multi-task teaching' shows nevertheless that it is a time consuming job; a fact that unavoidably causes a number of difficulties. I will argue that these difficulties are increased and reinforced by the particular position any post-graduate who teaches find themselves in, and which are not fully recognised by departments.

On first sight it seems that post-graduates are well suited for the task of teaching. Being young and having only recently finished their degrees, they are very close to undergraduate students and should be able to anticipate with their situation. A friend of mine for example will always let her students choose the subjects of the seminars in order to enable them to follow any particular interests they may have. She never had the chance to pursue her interests within the subject as an undergraduate because her teacher was not prepared to spend time and effort on drawing up new seminars the topics of which may be outside his specialisation. She takes this time today in order to further her students' interest in the subject. 
Knowing the staff of the department postgraduate teachers may also be able to sense certain flaws in the courses in which they are involved. This may hold true for tutors in particular because they interact more closely with the students in the classes than the actual lecturer does. Whatever the reasons for problems with a lecture -- be they related to structure, content or its delivery -- with their knowledge of the staff, their critical distance to the course and their closeness to the students tutors are in a unique position to detect such problems. As a tutor on a course which was conducted by three different lecturers I, for example, found myself to be the only constant contact for the undergraduate students over the course of the academic year. The lecture was organised in such a way that every member of staff focused on their research expertise moving from small scale hunter-gatherer societies, via agricultural societies to modern states; all these areas intermingled with anthropological theory and research methods. It was my task to bring all these different areas together in the tutorials and to connect them in a more consistent picture of the discipline; this despite the fact that such an aim was not expressed in the outline of the tutorials.

Post-graduate teachers have ar supposed ability to anticipate student needs due to their own recent student experience. This is why some try so hard. After some inquiries in Durham it appears that post-graduates spent substantially more time on marking essays than regular staff. This includes giving their students proper feedback, even one to one feedback as is the case amongst the post-graduates in the department of history. This although they are not being paid for consultation. The actual time which these post-graduates spent on essay marking ranges from 'about an hour, but not more than an hour and a half per essay', 'one hour and a half per essay' to 'at least one hour and a half per essay'. One must admit that this is an impressive effort. However, this conscientiousness of post-graduate teachers has critical consequences. Some supervisors seem to believe that it affects their students' Ph.D. work: 'my supervisor says I spend too much time marking', 'my supervisor would not want me to teach this course because I take too much time for preparation'. I myself was greeted with astonishment when I presented a type written page of comments that I had prepared for each essay I marked whilst trying to spend as little time on the marking as possible; already feeling bad about rushing through the essays.

This noticeable amount of time for marking needs to be added to the time spent on preparing the classes and the administrative work. For example, only copying samples of formative work took me about an hour for two tutorial groups last year. 
Administrative duties are even heavier for summative work where double marking needs to be arranged, essays exchanged, marks negotiated etc.

As the comments of supervisors above show, the hard work many postgraduates put into teaching is not always appreciated; it rather often remains unnoticed by the institution. I will argue that this is due to the same fact which makes post-graduates so suitable for teaching: their closeness to the students, their unbroken enthusiasm; the very fact that they themselves are still students.

From the point of view of the undergraduate students they teach the postgraduates are teachers, they are staff. At least they are supposed to be regarded as such and many go to lengths to achieve the respect other members of staff seem to gain more easily by virtue of age and status. As a friend of mine puts it, as a young post-graduate he always faces some difficult first weeks in the academic year because he has to establish his authority as a teacher within the classroom. He believes that post-graduate students generally experience more difficulties with discipline due to their lack of advancement in age --they are not the 'middle aged bloke with a beard'- and the missing 'D.Phil.' after their name. Although I am not sure whether disciplinary problems are indeed greater in classes taught by postgraduates in contrast to those taught by more senior members of staff, I can see a point in case. Teaching students are often painfully aware of the fact that they need to gain the status of a teacher in front of the class which in turn leads to the necessity to justify the trust the students put into them. In consequence, this gained recognition as a teacher obligates them to present whatever they teach with authority and conviction. In the atmosphere of the classroom they therefore appear fully responsible for the course despite the fact that this course was drawn up and is administered by someone else. In tutoring in particular the tutor will be teaching whatever the lecturers find suitable and necessary; even the way in which it is taught might be prescribed by the department. This may in general not result in any major problems; it is even helpful in that it reduces the amount of time tutors need to spent on teaching preparation. However, the awkwardness of the situation becomes crystalclear when there is a problem with the course.

I am certain that stories similar to this have happened and are happening in a number of departments. Due to problems with the course the staff may decide to change the topic of the upcoming tutorial. The tutoring post-graduates are not included in the process of decision-making and consequently somewhat baffled when 
they are informed about the change. Inquiries that are brought forward in a critical manner do not result in a successful explanation. The post-graduates feel in an awkward position since they will stand in 'front line' and will have to justify this change to their students. One may imagine that a meeting of staff and tutors about the course is considered but due to time constraints on both sides never takes place (everyone can imagine how hard it is to get six or seven people around a table, especially if one of them is a course team leader). If the tutors feel that problems with the course persist they will keep complaining or, as they will see it, continue to make constructive suggestions for an improvement of the course. On the other side members of staff may feel criticised in their personal actions and abilities. This is certainly a difficult situation for all but one that illustrates very well the position of post-graduate teachers. Whilst their students regard them as the authoritative figure of the teacher; the staff sees them as a student, which they also are. Rather than being in a liminal or even liminoid position (Turner 1967; 1992) it seems that the postgraduate teacher is doubly defined in conflicting roles. For a liminal status the situation of these teachers lacks a structured 'unstructured' phase (Turner 1967:93111). In contrast the post-graduate teachers are quite clearly defined, both as students and as teachers. It seems to me that this double definition accounts for many of the difficulties teaching postgraduates experience. This is due to the fact that the two identities of the 'student-teachers' link them to two different positions in a hierarchical system. From this point of view it is telling that when I sent an email on this topic to friends two of them mentioned the word 'empowerment' in their reply. They pointed out that they had not felt empowered as 'teachers' when they were graduate students. This point is also apparent in the example of the tutors who tried to improve the course (see above), and it similarly contributed to problems in another case. A post graduate student was asked to deliver a course as, due to various members of staff being on sabbatical leave, the teaching commitments of the remaining staff would make it difficult for them to deliver the course that year. At the time there was some debate as to the effectiveness of putting large amounts of teaching material onto an electronic blackboard system which students could then read and print out. Having discussed the various options with members of staff the post-graduate teacher decided, for a variety of reasons, not to use the system for anything other than weblinks and duplicating material handed out in lectures. However, because she was a 'student' she was not privy to the meetings where these issues were discussed and, following a request from one student, it was 
decided by the course leader that her material should indeed be posted online. This was not done with the intention of undermining her. However, because she was not addressed personally until after that decision had been made her already limited power about the course she taught was diminished. All that remained for the moment was she as a mere deliverer of content but not as a teacher. ${ }^{1}$

As pointed out before post-graduates and other part-time staff usually deliver courses drawn up and maintained by other members of the faculty. How much power, if any, they have over course outlines, contents of lectures and classes, marking procedures is unclear at best. However, even if they were allowed to take a freer reign on how they teach many of these teachers would not have the time to spent on changing course contents, seminars and lectures. This especially if the course does not relate directly to their own research topic which seems to be the norm rather than the exception. This apparent lack of 'sufficient' time for teaching preparation is another rather frustrating aspect of the 'part-time teaching experience', as I often find myself. This has two reasons: there is the simple fact that one may want to help the younger students and feels unable to do so if one barely knows the content of the seminars oneself. Even more important is, however, that postgraduates are still learning to teach. They therefore aim to make their first teaching experience a good experience from which training and knowledge can be gained. This goal is hindered greatly by the lack of time and money many graduate students face.

This brings us back to the generally difficult position of those in transition to an 'academic'. Academics, as we know now, do not only distinguish themselves through research, writing and teaching but also by age and status, the symbolic DPhil or Prof. by their name. Although knowing the ideal postgraduate life as managing all four tasks of writing up, in time, publishing, teaching most students have to make choices between these three tasks and the often very real necessity of earning money as well.

Many will in consequence turn to pragmatics as regards teaching. I heard more than once from friends who were asked to help out with teaching: 'Yes, but only if they pay me'. Tutors who critically engage with their teaching, make suggestions for

\footnotetext{
${ }^{1}$ The postgraduate student concerned would like to point out that when she was addressed personally her opinions were taken into consideration and her decision was the one that was implemented. She comments "I do think that the problem of the double definition is one that some members of staff are aware of and would like to do something about - but the 'systems that be' don't easily allow that."
} 
improvements and feel rejected in their efforts will conclude that it is not worth continuing to teach in this manner, since: 'Its not worth the hassle' and also 'The payment is not good enough for the nerves you loose on this'. So, how can the multitask of teaching be reduced to a manageable duty one may ask? Interestingly enough it seems that the connected administrative tasks in particular cannot be neglected because they are usually monitored closely by the department. They therefore have to be fulfilled. Does this mean that consequently the teaching in the class room suffers, since it emerges that this part of the duty is not observed by the department; or at least cannot be observed as easily? Speaking from experience it seems that many part-time teachers feel indeed that the quality of their teaching suffers. It appears though that many of them are actually delivering their courses quite well. This phenomenon is linked to an 'over-conscientiousness' of new teachers; see for example the time postgraduates spent marking. The fear not to be a good teacher because of time constraints and the difficulties of juggling too many tasks was expressed to me by a friend:

However, at the end of the day, the main priority of a postgraduate is his/her $\mathrm{PhD}$, so yes there is a juggling act... I have found the effects to be twofold; first, I have had to sacrifice time I would spend on my PhD to research the topic I needed to teach; second, I have often felt that I should be better prepared for my teaching... This leads to the worry that you may not be able to tutor the students to a sufficient level, and to question how good a tutor you can be of tutoring is not your main priority. (Boniface 2002, personal conversation)

\section{To conclude:}

It seems to me that many postgraduates first actively seek teaching experience proudly looking forward to the prospect and that most of them manage to deal with a modest amount of teaching. Those who teach a substantial amount of hours, maintain good contact to their undergraduate students, co-operate well within the department, and who are therefore often appreciated by the department, are the ones who struggle to finish their PhD; this sometimes close to the end of their fourth year. Although the quality of teaching does not seem to suffer as yet despite the limitations on their time, many graduate students feel that with more time at their hands they would be able to improve the teaching. 
As pointed out above this over-conscientiousness of new staff in respect to teaching is linked to the fact that they are still learning to teach. This is why they want to make their first opportunities to teach a good experience enabling them to use it as training for the future. The question is therefore not whether post-graduate students manage to juggle doing the Ph.D., publishing and teaching (including administration). The question is whether they manage to balance finishing their Ph.D. on time, publishing and teaching well. I believe that this question has to be answered with a 'No'. It furthermore seems to me that a failure on behalf of the department to recognise the particular and most resourceful position of postgraduates increases the problems the students face. However, how they manage to juggle these different tasks depends on the individual student. Modesty in the amount of teaching that is conducted seems to be unavoidable, often also taking an extension for the Ph.D. The amount of publishing postgraduates manage during their studies varies greatly as well. Most of them are, however, aware that publications are a necessity for future success in the profession whereas curiously enough the amount and even more so the quality of teaching experiences do not always seem to be a priority for future employers (see below).

\section{Monitored by department or University}

PhD.: Time spent on it

Publications: N/A

Teaching: amount of courses (lack of lecturing staff); administrative duties

\section{Necessary for academic qualification:}

Ph.D.

Publications: amount of

Teaching experience: amount of

The careful reader may have noted that none of the tables above include the question of the quality of the teaching that was conducted. Although future employees may hope that more teaching also means better teaching many do not seem to assess or even question the teaching abilities of their future employees. As will be clear to most this tendency seems to be linked primarily to the importance RAE standards and therefore research excellence have achieved in our departments. However, it nevertheless remains to be asked critically whether the quality of the 
teaching experience should really only matter to the post-graduate students and new staff.

...I believe that students' motivation and intention also affects their learning outcomes, as these factors shape the learning approach students adopt... What research amongst history undergraduates found, however, is that students value enthusiasm and passion for the subject in their teachers. It is truism that inspirational university teachers can, and do, inspire; and many students in receipt of such teaching will be motivated to take a deep approach to that subject. (Hartland 2002; assignment for a teaching certificate)

\section{Literature:}

Hartland, Beth. 2002. Reflective overview [unpublished assignment for the postgraduate teaching certificate]. Durham.

Turner, Victor. 1992. The anthropology of performance. New York: PAJ Publications.

Turner, Victor 1967. The forest of symbols. Ithaca, New York: Cornell University Press.

Anselma Gallinat has studied Anthropology, History and Media Sciences as part of a Masters program at the University of Goettingen before she came to Durham to do her Ph.D. in Social Anthropology. She finished this Ph.D. in 2002 and is now working as a part-time tutor in Anthropology at Durham and Queens Campus, Stockton (Durham). Her work is concerned with the dynamics of socio-cultural change and identities in eastern Germany. Her thesis compared public and grass-roots level discourses on and individual experiences of change and continuity in the postsocialist society. 